\title{
Associations of urological malignancies with renal progression and mortality in advanced chronic kidney disease: a propensity-matched cohort study
}

\author{
Rajkumar Chinnadurai ${ }^{12^{*}}$ (D), Noel W. Clarke ${ }^{3,4}$ and Philip A. Kalra ${ }^{1,2}$
}

\begin{abstract}
Background: Urological malignancy (UM) in patients with chronic kidney disease (CKD) is an added burden to their overall morbidity and mortality. UM is itself a common cause of CKD. Understanding the associations of UM with outcomes in advanced CKD can help in optimisation of the management of these patients. This study investigates the distribution and association of urological malignancy with outcomes (renal progression and mortality) in patients with advanced non-dialysis dependent CKD.

Methods: The study was conducted in 2637 of 3115 patients recruited in the Salford Kidney Study between the years 2002 and 2016. A comparative analysis was performed between 160 patients with UM (at baseline and incident) and 2477 patients with no malignancy. Cox-regression models and Kaplan-Meir estimates were used to explore the association between the presence of UM with mortality and renal outcome. Linear regression analysis was used to calculate the rate of progression of CKD in the groups. A 1:3 propensity score matched cohort of 640 patients was generated and utilised in the above analyses.

Results: $4.4 \%$ had a history of UM at baseline with the annual incident rate being $0.37 \%$. The site of malignancy was the kidney in 40\% with comparable numbers for prostatic malignancy (39\%). $70 \%$ (111/160) of UM patients had a medical cause as their primary diagnosis for CKD. Over a median follow up of 4 years, 34\% (905) patients died. In the matched sample, the proportion of deaths was similar between the groups (UM 44\% versus no malignancy 48\%, $p=0.36$ ). 30\% reached end-stage renal disease (ESRD) with no difference between the groups. In the Coxregression model, UM did not prove to be a risk factor associated with either all-cause mortality (HR:1.03; Cl: 0.791.35; $p=0.81$ ) or reaching ESRD (HR:1.12; Cl: 0.80-1.58; $p=0.49$ ). The rate of decline in estimated glomerular filtration rate (eGFR) was similar between the groups $\left(-1.05 \mathrm{vs}-1.25 \mathrm{~mL} / \mathrm{min} / 1.73 \mathrm{~m}^{2} /\right.$ year, $\left.p=0.31\right)$.

(Continued on next page)
\end{abstract}

\footnotetext{
* Correspondence: rajkumar.chinnadurai@srft.nhs.uk

'Department of Renal Medicine, Salford Royal NHS Foundation Trust, Salford

M6 8HD, UK

${ }^{2}$ Faculty of Biology, Medicine and Health, University of Manchester,

Manchester, UK

Full list of author information is available at the end of the article
}

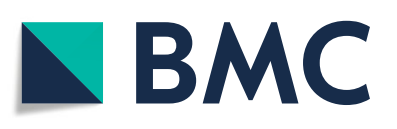

(- The Author(s). 2020 Open Access This article is licensed under a Creative Commons Attribution 4.0 International License, which permits use, sharing, adaptation, distribution and reproduction in any medium or format, as long as you give appropriate credit to the original author(s) and the source, provide a link to the Creative Commons licence, and indicate if changes were made. The images or other third party material in this article are included in the article's Creative Commons licence, unless indicated otherwise in a credit line to the material. If material is not included in the article's Creative Commons licence and your intended use is not permitted by statutory regulation or exceeds the permitted use, you will need to obtain permission directly from the copyright holder. To view a copy of this licence, visit http://creativecommons.org/licenses/by/4.0/ The Creative Commons Public Domain Dedication waiver (http://creativecommons.org/publicdomain/zero/1.0/) applies to the data made available in this article, unless otherwise stated in a credit line to the data. 
(Continued from previous page)

Conclusions: There was no correlation observed between UM and all-cause mortality or ESRD. Medical causes of

CKD have a significant influence on the outcomes in patients with UM, whereas the UM did not. Hence, a

coordinated approach with early liaison between the urology and nephrology teams is needed in the management of UM patients with CKD.

Keywords: Urological malignancies, CKD, All-cause mortality, Renal progression

\section{Background}

Urological malignancies (UM), including malignancies of prostate, kidney, urinary bladder and urinary tract, are highly prevalent in chronic kidney disease (CKD) patients [1]. UM can be the cause or a consequence of CKD. The cause of CKD in patients with UM is often multifactorial, and relevant factors are the site of malignancy (kidneys), urinary tract obstruction and factors related to treatment (chemotherapy, surgery). Several studies have shown an association between CKD and incident UM [1]. Pathogenetic factors have been postulated to include the chronic inflammation, oxidative stress and uremic toxins of CKD as possible triggers $[2,3]$.

UM in patients with CKD has been shown to be associated with poor prognosis $[4,5]$. Further, the postsurgical prognosis of UM is shown to be poor in patients with preoperative CKD due to medical causes [6]. CKD is reported to be a significant risk factor associated with cancer-specific mortality, in particular to cancers of the kidney and urinary tract [7].

Healthcare workers in nephrology and urology work in tandem to prevent the onset and slow the progression of CKD in patients with urological malignancy. Nephrologists are often involved in pre-operative optimisation of UM patients prior to urological intervention, or in follow-up post-intervention. Urologists are in constant pursuit of innovative approaches in the management of these cancers including nephron sparing procedures and robotic surgeries to produce better outcomes. However, the impact of UM malignancies and their management (medical or surgical) on renal outcomes (CKD progression and reaching end-stage renal disease) and consequent overall mortality in advanced CKD (non-dialysis dependent CKD, stage 3-5) patients is still underexplored. Hence, this study aimed to investigate the associations of urological malignancies with mortality and renal outcomes in a large non-dialysis CKD cohort.

\section{Methods}

\section{Sampling}

This study was conducted in Salford Kidney Study (SKS) patients: this is a large prospective CKD cohort recruiting patients since the year 2002. The SKS was previously known as the Chronic Renal Insufficiency Standards Implementation Study (CRISIS). Patient recruitment into
SKS has been described in the earlier published literature $[8,9]$. Briefly, any adult patient with age $>18$ years and eGFR $<60 \mathrm{~mL} / \mathrm{min} / 1.73 \mathrm{~m}^{2}$ referred to the Salford renal service (a tertiary hospital for renal care in the United Kingdom with 1.55 million catchment population) can be approached for consent to the study. Acute kidney injury patients and those who are in immediate need for commencing renal replacement therapy (RRT) are excluded from enrolment in this study as the principal objective of the SKS was to study the cardiovascular disease outcomes during longitudinal follow-up of CKD patients. At study baseline, demographics, comorbidities including the history of cardiovascular events and malignancy, clinical variables and concurrent medications are collected. Baseline blood results including full renal profile, full blood count and bone profile are also recorded. The patients are then followed up on an annual basis to update their comorbidities, hospital admissions, medications and blood results. Data is collected and updated by a dedicated team of research nurses.

Of the 3115 patients enrolled in SKS between October 2002 and December 2016, 2952 patients had a complete dataset and minimum 6 months follow-up data. After excluding patients with all other malignancies (both prevalent and incident), 2637 patients were included in this study. From this sample, 160 patients with a history of urological (kidney, prostate, bladder and urinary tract) malignancies were identified (131 at baseline and 29 incident cases during follow-up). A comparative analysis was performed between patients with urological malignancy (160) and those without any malignancy (2477). A 1:3 propensity score matched sample of 640 patients (urological malignancy 160 patients: no malignancy 480 patients) was produced and used for similar analysis. A flowchart illustrating patient recruitment to the study is shown in Fig. 1.

\section{Data collection}

Patients were followed up from study entry (baseline) to endpoints which included commencing RRT, death, lost to follow up or study end date of 31st December 2017. For patients with incident urological malignancy, the study visit before their cancer diagnosis was used as the study baseline and patients were followed-up until the above endpoints had been reached. Baseline blood results included tests undertaken at the baseline date or within 3 


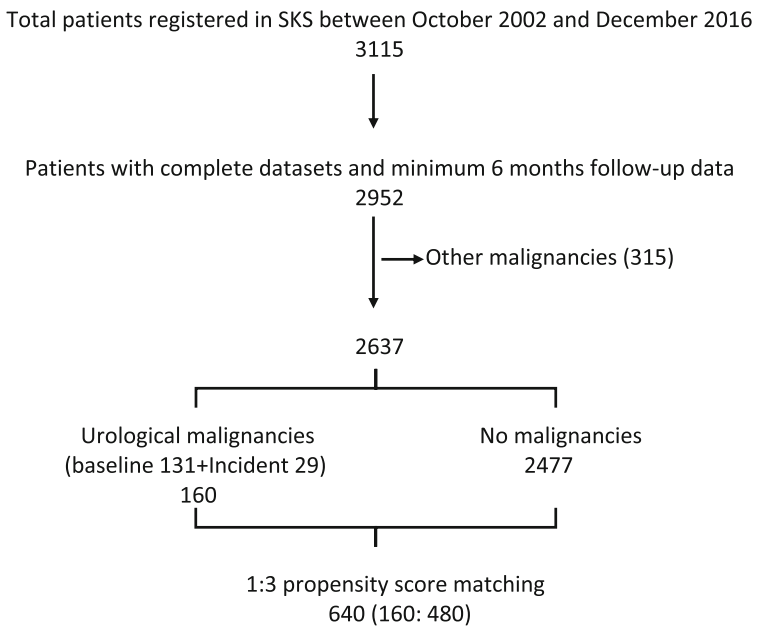

Fig. 1 Flowchart of patient recruitment to the study

months of study entry date. For calculating the rate of decline in CKD, eGFR results only from outpatient clinic visits were used, and only patients with a minimum of three eGFR measurements were included in this analysis.

\section{Study definitions}

A smoking history was defined as a history of smoking irrespective of the number of cigarettes smoked, similarly an alcohol history was defined as alcohol intake irrespective of the number of units of alcohol. A comorbidity of hypertension was defined as a history of hypertension recorded in the hospital or general practitioner's records, and/or receiving antihypertensive therapy. End-stage renal disease (ESRD) was defined as reaching renal replacement therapy (RRT) or eGFR of $<10 \mathrm{~mL} / \mathrm{min} / 1.73 \mathrm{~m}^{2}$ (to capture patients opting for conservative care). RRT included haemodialysis, peritoneal dialysis and transplantation. Non-fatal cardiovascular events (NFCVE) included a composite of non-fatal cardiac arrest, acute coronary syndrome, myocardial infarction, peripheral vascular disease, cerebrovascular accident and congestive cardiac failure (new diagnosis or hospital admission with exacerbations). Coding for primary renal diagnosis for CKD was based on the European Renal Association and European Dialysis and Transplant Association (ERA-EDTA) coding system. The cause of death data was obtained from the death certificate obtained from the Office of National Statistics and from electronic patient records (EPR).

\section{Statistics}

Statistical analysis was performed using SPSS version-23, licenced to the University of Manchester. Throughout the analysis, categorical values were expressed as number (\%), and the $p$-value was derived using the Chi-square test. Most of the data in SKS is non-normally distributed hence for uniformity, continuous values were expressed as median (interquartile range) and the Mann-Whitney $\mathrm{U}$ test was used to calculate the $p$-value. A $p$-value $<0.05$ was considered statistically significant in this study. Univariate and multivariate Cox-regression models were used to study the association between the presence of urological malignancy, all-cause mortality and reaching endstage renal disease. To overcome competing risk the follow-up time was censored at the first occurring event in these models [10]. Kaplan-Meier curves were also used for a visual demonstration of these associations, with the log-rank test used for statistical significance in this estimate. Linear regression analysis was used to generate the annual rate of change in eGFR (delta GFR). A competing risk analysis (CRA) for RRT and death between the groups was also performed using the 'cmprsk' and 'survival' packages in $\mathrm{R}$ software, version 3.5.1 [11, 12]. A $p$-value for the CRA was calculated by the modified $\mathrm{X}^{2}$ statistic outlined in Gray, 1988 [13]. Patients with urological malignancies were matched with those without any malignancy using propensity score matching. Matching was undertaken for the four major variables that were significantly different between the groups: age, gender, ethnicity and smoking status. The groups were matched 1:3 using the neighbour match of patients with the same propensity score, generated by 'MatchIt' package of the R software version 3.5.1 [14].

\section{Results}

At baseline, 4.4\% (131/2952) of our cohort had a history of UM (prior UM or current UM at study recruitment into the cohort) and the annual incident rate was $0.37 \%$. Renal malignancy was the most common prevalent site and prostate the commonest incident site (Fig. 2). Management options for UM were found to be variable ranging from radical resection to routine surveillance depending on the site. $61 / 160$ patients had unilateral nephrectomy (partial or total), and 10/160 had radical cystoprostatectomy (Additional file 1: Table S1). The coded primary renal diagnosis for CKD in UM patients is illustrated in Fig. 3. 30\% of UM patients had a primary diagnosis of kidney tumour and/or urological surgery while the remaining $70 \%(111 / 160)$ of UM patients had a medical cause as their primary diagnosis for CKD.

The median age of our sample was 67 (interquartile range 55 to 75$)$ years. Our cohort had a predominance of males (63\%) and Caucasians (96\%). A higher percentage of patients with UM smoked compared to those without any malignancy $(72.5 \%$ versus $64.7 \%, p<0.05)$. $33 \%$ of the patients in our cohort had diabetes, with $90 \%$ having a history of hypertension. The baseline cardiovascular risk factor profile of the groups was similar. The groups were matched in respect to other baseline characteristics apart from more patients in the no malignancy group having chronic obstructive pulmonary disease $(18.5 \%$ versus $11.8 \%, P=0.03)$ and more receiving renin-angiotensin 


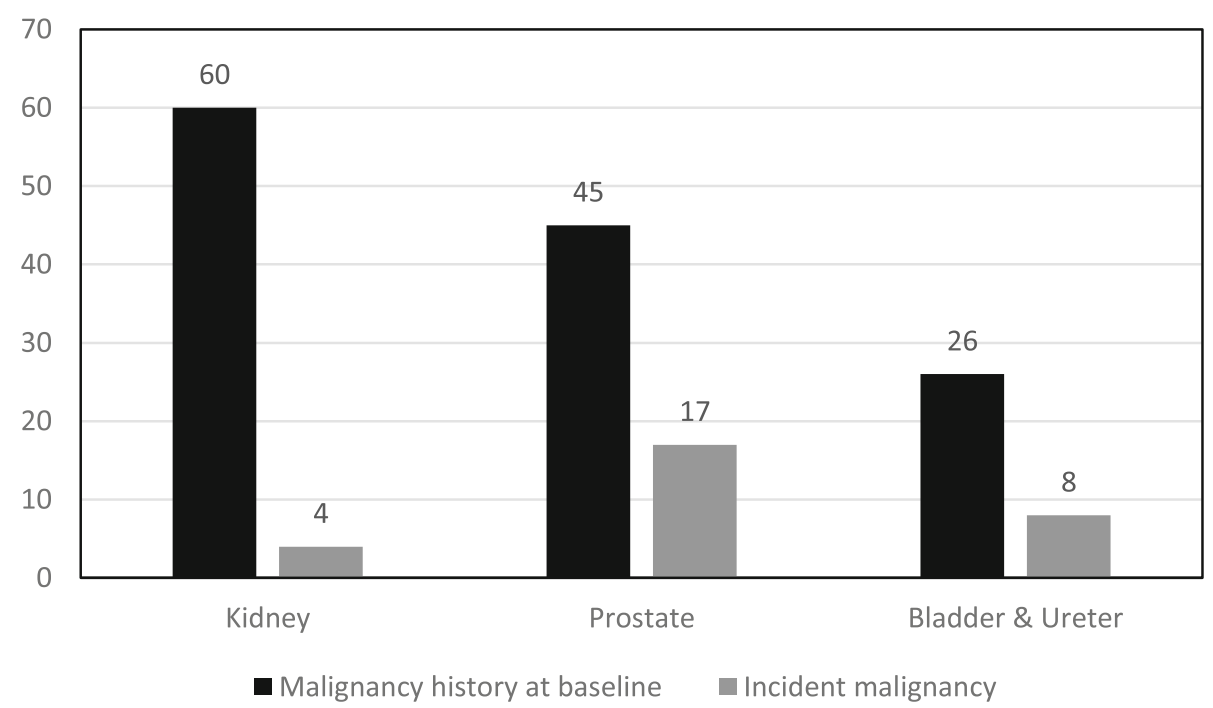

Fig. 2 Urological malignancy site distribution

system (RAS) blockers (62.5\% versus $43.8 \%, p<0.001)$. Patients with UM had a higher creatinine leading to a lower eGFR (27.7 vs $30.3, p<0.05)$. Once matched by propensity scores, the groups were similar in most of the baseline characteristics and blood results (Table 1).

A total of $905(34 \%)$ patients died over a median follow-up of 48 months. The all-cause mortality was noted to be higher in the UM group $(43.8 \%$ versus $33.7 \%, p=0.01$ ), but this difference disappeared once the groups were matched. The cause of death data was available only in $52.6 \%$ (476/905) of the total number of deaths. Cancer-specific mortality was the leading cause of death in the UM group, while cardiovascular death was the leading cause in the no malignancy CKD group. However, the age at death was not significantly different between the groups (matched sample $p=0.56$ ). There was no difference observed between the groups with regard to reaching ESRD (28.1\% versus 29.5\%, $p=$ $0.70)$ and the uptake of RRT showed no difference $(17.5 \%$ versus $21.8 \%, p=0.20)$. Further, the CKD progression as determined by the linear regression analysis showed that the annual rate of decline in eGFR was similar between the groups $(-1.05$ versus $-1.25 \mathrm{~mL} /$ $\left.\min / 1.73 \mathrm{~m}^{2}, p=0.31\right)$. Also, the number of NFCVE were similar between the groups in both the total and matched sample (Table 2).

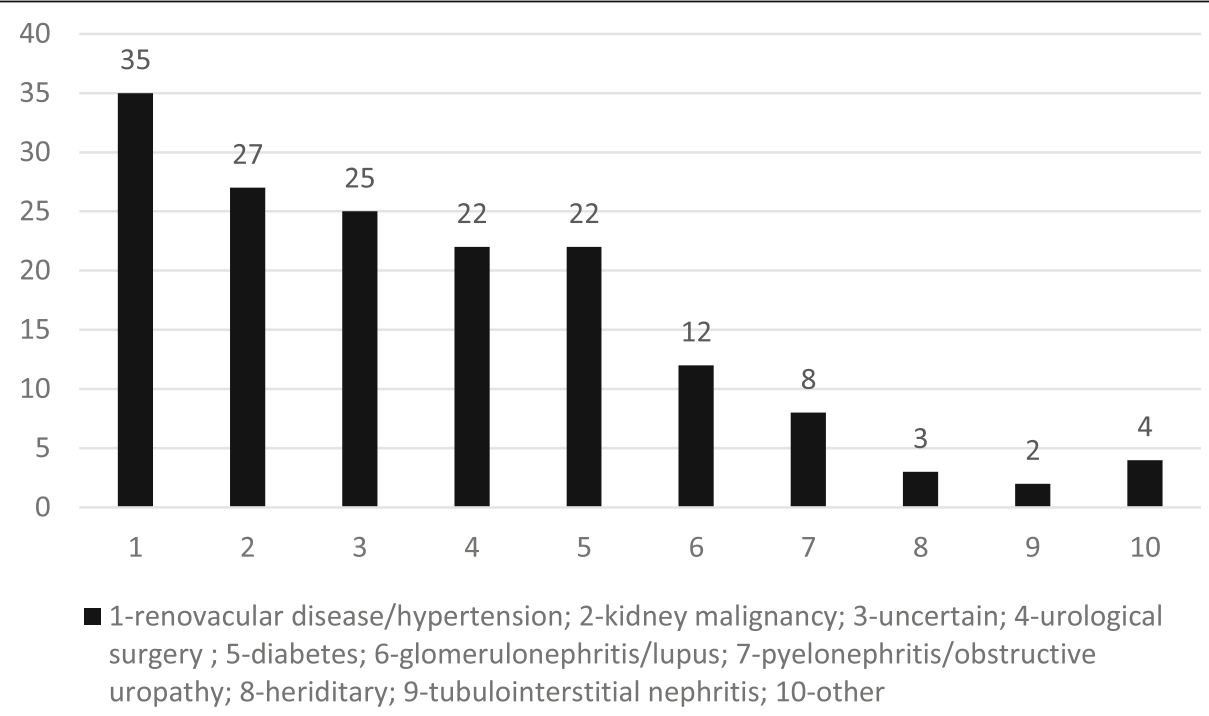

Fig. 3 Coded primary renal diagnosis in patients with urological malignancy 
Table 1 Comparison of baseline characteristics between patients with urological malignancy and no malignancy (total and matched sample)

\begin{tabular}{|c|c|c|c|c|c|c|c|c|}
\hline \multirow[b]{2}{*}{ Variable } & \multirow[b]{2}{*}{ Total (2637) } & \multicolumn{4}{|l|}{ Total sample } & \multicolumn{3}{|l|}{ Matched sample } \\
\hline & & $\begin{array}{l}\text { Urological malignancy } \\
\text { (UM) (160) }\end{array}$ & $\begin{array}{l}\text { No malignancy } \\
\text { (NM) (2477) }\end{array}$ & $\begin{array}{l}p \text {-Value } \\
\text { UM vs } \\
\text { NM }\end{array}$ & Total (640) & $\begin{array}{l}\text { Urological malignancy } \\
\text { (UM) (160) }\end{array}$ & $\begin{array}{l}\text { No malignancy } \\
\text { (NM) (480) }\end{array}$ & $\begin{array}{l}p \text {-Value } \\
\text { UM vs } \\
\text { NM }\end{array}$ \\
\hline Age, years & $67(55-75.5)$ & $72.5(66.6-77.4)$ & $66.5(54.3-75.3)$ & $<0.001$ & $72.5(66.6-77.5)$ & $72.5(66.6-77.4)$ & $72.4(66.6-77.5)$ & 0.97 \\
\hline Gender, male & $1652(62.6)$ & $138(86.3)$ & $1514(61.1)$ & $<0.001$ & $550(85.9)$ & $138(86.3)$ & $412(85.8)$ & 0.90 \\
\hline Caucasian & $2524(95.7)$ & $159(99.4)$ & 2365 (95.5) & 0.02 & $638(99.7)$ & $159(99.4)$ & 479 (99.8) & 0.41 \\
\hline Smoking & $1719(67.2)$ & $116(72.5)$ & $1603(64.7)$ & 0.04 & $478(74.7)$ & $116(72.5)$ & $362(75.4)$ & 0.46 \\
\hline Alcohol & $1236(46.87)$ & $77(48.1)$ & 1159 (46.79) & 0.74 & $315(49.2)$ & $77(48.1)$ & $238(49.6)$ & 0.75 \\
\hline $\mathrm{BMI}^{\mathrm{a}}, \mathrm{kg} / \mathrm{m}^{2}$ & $28.1(24.7-32.6)$ & $28.1(25.7-32.3)$ & $28.1(24.6-32.6)$ & 0.55 & $28.1(25-32)$ & $28(25.7-32.3)$ & $28.2(24.9-32)$ & 0.48 \\
\hline Systolic BP, mmHg & $138(124-152)$ & $140(130-154)$ & $138(123-152)$ & 0.08 & $140(128-155)$ & $140(130-154)$ & $140(127-155)$ & 0.92 \\
\hline Diastolic BP, mmHg & $75(66-80)$ & $75.5(66-82)$ & $75(66-80)$ & 0.26 & $72(65-80)$ & $75(66-82)$ & $72(64-80)$ & 0.02 \\
\hline Hypertension & $2397(90.9)$ & $140(87.5)$ & 2257 (91.1) & 0.12 & $579(90.5)$ & $140(87.5)$ & $439(91.5)$ & 0.14 \\
\hline DM & $866(32.8)$ & $53(33.1)$ & $813(32.8)$ & 0.94 & $244(38.1)$ & $53(33.1)$ & $191(39.8)$ & 0.13 \\
\hline IHD & $492(18.65)$ & $34(21.3)$ & $458(18.5)$ & 0.39 & $46(7.2)$ & $34(21.3)$ & $112(23.3)$ & 0.59 \\
\hline Ml & $414(15.7)$ & $33(20.6)$ & $381(15.4)$ & 0.08 & $150(23.4)$ & $33(20.9)$ & $117(24.4)$ & 0.33 \\
\hline CCF & $454(17.2)$ & $25(15.6)$ & $429(17.3)$ & 0.58 & $128(20)$ & $25(15.8)$ & $103(21.5)$ & 0.11 \\
\hline CVA & $214(8.1)$ & $16(10)$ & $198(7.99)$ & 0.37 & $66(10.3)$ & $16(10)$ & $50(10.4)$ & 0.88 \\
\hline PVD & 347 (13.2) & $18(11.3)$ & $329(13.3)$ & 0.46 & 106 (16.6) & $18(11.4)$ & $68(14.2)$ & 0.35 \\
\hline COPD & $478(18.1)$ & 19 (11.8) & $459(18.5)$ & 0.03 & $113(17.6)$ & $19(12.1)$ & 94 (19.6) & 0.03 \\
\hline CLD & $79(2.9)$ & $1(0.63)$ & $78(3.1)$ & 0.07 & $12(1.87)$ & $1(0.63)$ & $11(2.29)$ & 0.18 \\
\hline RAS blocker & $1618(61.4)$ & $70(43.8)$ & $1548(62.5)$ & $<0.001$ & $355(55.5)$ & $70(44.3)$ & $285(59.3)$ & 0.001 \\
\hline Statin & 1545 (58.6) & $95(59.4)$ & $1450(58.5)$ & 0.84 & $415(64.8)$ & $95(59.4)$ & $320(66.6)$ & 0.09 \\
\hline ESA & $340(12.9)$ & $14(8.8)$ & $326(13.2)$ & 0.11 & $84(13.1)$ & $14(8.9)$ & $70(14.6)$ & 0.06 \\
\hline $\mathrm{Hb}, \mathrm{g} / \mathrm{L}$ & $123(112-136)$ & $124(113-137)$ & $123(112-135)$ & 0.67 & $123(112-135)$ & $124(113-137)$ & $123(112-135)$ & 0.57 \\
\hline ALP, Units/L & $82(65-103)$ & $83(66-100)$ & $81(65-103)$ & 0.67 & $82(66-102)$ & $83(66-101)$ & $81(66-102)$ & 0.64 \\
\hline Calcium, mmol/L & $2.30(2.21-2.39)$ & $2.31(2.22-2.37)$ & $2.30(2.21-2.39)$ & 0.91 & $2.30(2.20-2.37)$ & $2.31(2.22-2.37)$ & $2.30(2.20-2.37)$ & 0.28 \\
\hline Phosphate, mmol/L & $1.12(0.97-1.28)$ & $1.09(0.93-1.26)$ & $1.12(0.97-1.29)$ & 0.04 & $1.07(0.94-1.25)$ & $1.09(0.93-1.26)$ & $1.07(0.94-1.25)$ & 0.96 \\
\hline $\mathrm{uPCR}^{\mathrm{b}}, \mathrm{g} / \mathrm{mol}$ & $31(13-107)$ & $32.6(12.9-93.4)$ & $31.33(13.04-107.7)$ & 0.63 & $25.3(12.5-85.3)$ & $32.6(12.9-88.2)$ & $24.4(12.4-82.8)$ & 0.37 \\
\hline Creatinine, micromol/L & $181(135-256)$ & $197(151-286)$ & $179(135-254)$ & 0.004 & $190(145-274.7)$ & $197(151-286)$ & $189(144-272)$ & 0.25 \\
\hline $\mathrm{eGFR}, \mathrm{mL} / \mathrm{min} / 1.73 \mathrm{~m}^{2}$ & $30(20-42.9)$ & $27.7(17.5-39.1)$ & $30.3(19.8-43.2)$ & 0.03 & $28.6(18.1-39.8)$ & $27.75(17.5-39.1)$ & $28.8(18.5-40.1)$ & 0.41 \\
\hline
\end{tabular}

$B M I$ body mass index, $B P$ blood pressure $(\mathrm{mm}$ of $\mathrm{Hg}$ ), $D M$ diabetes mellitus, $I H D$ ischemic heart disease, $M I$ myocardial infarction, $C C F$ congestive cardiac failure, $C V A$ cerebrovascular accident, $P V D$ peripheral vascular disease, COPD chronic obstructive pulmonary disease, CLD chronic liver disease, RAS renin-angiotensin system, ESA erythropoietin stimulating agents, $H b$ haemoglobin, ALP alkaline phosphatase, $U P C R$ urine protein creatinine ratio, eGFR estimated glomerular filtration rate calculated by CKDEPI equation. Continuous variables are expressed as median (interquartile range) and $p$-Value by Mann-Whitney $U$ test

Categorical variables are expressed as number (\%) and $p$-Value by Chi-Square test

aMI missing in 469 of 2477 of total sample and in 112 of 640 of matched sample

${ }^{b}$ Missing uPCR values in 265 patients of total sample and 66 patients in matched sample

The univariate Cox-regression model showed a strong association between the presence of urological malignancy and all-cause mortality (HR:1.62, $p<0.001)$. However, the significance was lost in the multivariate model that was adjusted for age, gender and ethnicity (HR; $1.26, P=0.06$ ). Similarly, there was no association noted in the matched sample even in the univariate model (HR: 1.03, $p=0.81$ ) (Table 3 and Additional file 1: Table S2). The Kaplan-Meier curve for all-cause mortality showed no survival difference between the groups in the matched sample (Log-Rank test: $p=0.81$ ) (Fig. 4a).

There was no correlation between the presence of urological malignancy and reaching ESRD. (Table 3 and Additional file 1: Table S3). Lack of correlation in reaching ESRD is also shown in the Kaplan-Meier curve by RRT free survival in patients with and without urological malignancy (Log-rank; $p=0.49$ ) (Fig. 4b).

In the competing risk analysis, the cumulative incidence of RRT was similar between the groups both at 5 years ( 0.16 versus 0.19$)$ and at 10 years $(0.22$ versus 0.26$), p=$ 0.279 , and the probability of reaching RRT also reflected this in the matched sample. In contrast, the cumulative incidence for death was noted to be greater in the urological malignancy group both at five ( 0.36 vs 0.24$)$ and 10 years ( 0.57 versus 0.44$), p=<0.001$. The difference between the groups in the cumulative incidence of death was not observed in the matched sample (Table 4). 
Table 2 Comparison of mortality and renal outcomes between patients with urological malignancy and no malignancy in both total and matched sample

\begin{tabular}{|c|c|c|c|c|c|c|c|}
\hline \multirow[b]{2}{*}{ Variable } & \multicolumn{4}{|l|}{ Total sample } & \multicolumn{3}{|l|}{ Matched sample } \\
\hline & Total (2637) & $\begin{array}{l}\text { Urological malignancy } \\
\text { (160) }\end{array}$ & $\begin{array}{l}\text { No malignancy } \\
(2477)\end{array}$ & $p$-Value & $\begin{array}{l}\text { Urological malignancy } \\
(160)\end{array}$ & $\begin{array}{l}\text { No malignancy } \\
(480)\end{array}$ & $\begin{array}{l}p- \\
\text { Value }\end{array}$ \\
\hline Follow up, months & $48(25.5-79)$ & $40.6(23.4-69.6)$ & $48.6(25.6-79.5)$ & 0.02 & $41.3(23.7-72.7)$ & $47.4(25.8-77.8)$ & 0.22 \\
\hline All-cause mortality & $905(34.3)$ & $70(43.75)$ & $835(33.7)$ & 0.01 & $70(43.8)$ & $230(47.9)$ & 0.36 \\
\hline $\begin{array}{l}\text { 1st Cause death } \\
\text { (Malignancy) }\end{array}$ & $11 / 476(2.3)$ & $11 / 40(27.5)$ & $0 / 436(0)$ & $<0.001^{\mathrm{a}}$ & $11 / 40(27.5)$ & $0 / 111$ & $\begin{array}{l}< \\
0.001^{\circ}\end{array}$ \\
\hline 1st Cause death (CVD) & 179/476 (37.6) & $7 / 40(17.5)$ & $172 / 436(39.4)$ & 0.006 & $7 / 40(17.5)$ & $53 / 111(47.7)$ & $\begin{array}{l}< \\
0.001\end{array}$ \\
\hline 1St Cause death (Infection) & 142/476 (29.8) & $10 / 40(25)$ & $132 / 436(30.3)$ & 0.49 & $10 / 40(25)$ & 29/111 (26.1) & 0.89 \\
\hline 1st Cause death (ESRD) & $55 / 476(11.6)$ & $4 / 40(10)$ & $51 / 436(11.7)$ & $1.00^{\mathrm{a}}$ & $4 / 40(10)$ & 9/111 (8.1) & $0.75^{\mathrm{a}}$ \\
\hline Age at death, years & 78.7 (72-84.4) & $79.4(73-83.8)$ & $78.6(72-84.4)$ & 0.50 & $78.8(72.9-83.7)$ & $79.4(74.5-83.6)$ & 0.56 \\
\hline ESRD & $777(29.5)$ & $45(28.1)$ & $732(29.5)$ & 0.70 & $45(28.1)$ & $131(27.3)$ & 0.84 \\
\hline RRT & $568(21.5)$ & $28(17.5)$ & $540(21.8)$ & 0.20 & $28(17.7)$ & $72(15)$ & 0.45 \\
\hline NFCVE & $251(9.5)$ & $17(10.6)$ & $234(9.4)$ & 0.24 & $17(10.6)$ & 59 (12.29) & 0.57 \\
\hline $\begin{array}{l}\text { Rate of decline of eGFR } \\
\text { (eGFR slope) } \\
\mathrm{mL} / \mathrm{min} / 1.73 \mathrm{~m}^{2} / \text { year }\end{array}$ & & $-1.05(-2.5$ to 0.52$)$ & $\begin{array}{l}-1.25(-3.27 \text { to } \\
0.51)\end{array}$ & 0.31 & $-1.05(-2.5$ to 0.52$)$ & $-0.88(-2.3$ to 0.61$)$ & 0.58 \\
\hline
\end{tabular}

Cause of death represents 1a cause of death in death certificate. Cause of death available only in $476 / 905$ patients of the total sample and $151 / 300$ patients of the matched sample. CVD- cardiovascular disease, RRT- renal replacement therapy, ESRD- end-stage renal disease, NFCVE- non-fatal cardiovascular events

Continuous variables are expressed as median (interquartile range) and $p$-Value by Mann-Whitney $\mathrm{U}$ test

Categorical variables are expressed as number (\%) and $p$-Value by Chi-square test

eGFR -estimated glomerular filtration rate calculated by CKD-EPI equation

eGFR slope was calculated on $2459 / 2637$ patients in total sample and 593/640 patients in matched sample with three or more eGFRs

${ }^{a} p$-Value by Fisher exact test

The sub-analysis of 160 patients with UM showed that, 47 patients had a history of malignancy more than 5 years from recruitment into the cohort (group A), 61 had a history of malignancy with diagnosis within 5 years of recruitment (group B), and 52 had concurrent and incident malignancy (group C). The CKD status before the onset of malignancy was not available for the $68 \%$ of patients with prior history of UM. There was no significant difference in the proportion of deaths between these 3 groups $(p=0.44)$. Similarly, the proportion of patients reaching ESRD and RRT uptake was similar between the groups (Table 5).

Kaplan Meier (KM) analysis of the subgroups (no malignancy, > 5 years, < 5 years, concurrent and incident) showed no distinction between the groups in survival outcomes $(\log$-rank, $p$-Value $=0.324)$ (Additional file 2 : Figure S1A). In a KM chart of outcomes of patients with different urological cancer sites in the matched sample, there was an overlap of the survival pattern. (log-rank, $p=0.278$ ) (Additional file 2: Figure S1B).

\section{Discussion}

Several studies have cited the presence of CKD as a poor prognostic marker for patients with urological malignancy $[15,16]$. The prevalence $(4.4 \%)$ and annual incident rates $(0.57 \%)$ of urological malignancies in our cohort was comparable to other observational studies in CKD patients $[2,17]$. The higher prevalence and low incidence of kidney cancers in our cohort probably reflects patients being referred to the nephrology service postoperatively for ongoing CKD monitoring. The coded primary diagnosis for the majority $(70 \%)$ of patients with UM was a medical cause, suggesting a multifactorial aetiology for their CKD progression. Patients with UM were older compared to those without, and age-related association with cancer is well documented [18]. There were more males in the UM group (86.3\% versus $61.1 \%$, $p<0.001$ ), likely due to the inclusion of prostate cancer. More patients in the UM group had a history of smoking and cigarette smoking is well known to be associated with genitourinary malignancy [19]. The propensity score matching produced a well-matched sample with minimal difference in these baseline or biochemical characteristics.

The median follow-up duration was significantly lower in the group with UM (40.6 versus 48.6 months, $p=$ 0.02 ), probably due to their older age at recruitment. Loss to follow-up is one of the endpoints of the Salford Kidney Study, but this did not affect the results of this study as only small numbers were lost to follow up ( $n=$ 87). All-cause mortality rate was higher in the UM group mainly attributed to malignancy specific death; however 
Table 3 Association of urological malignancy with all-cause mortality and reaching end-stage renal disease (Cox regression models)

\begin{tabular}{|c|c|c|c|c|}
\hline \multirow{2}{*}{\multicolumn{2}{|c|}{$\begin{array}{ll}\text { Total sample } \\
\text { HR }(95 \% \mathrm{Cl})\end{array}$}} & \multirow[t]{2}{*}{$p$-Value } & Matched sample & \multirow{2}{*}{$\begin{array}{l}p \text { - } \\
\text { Value }\end{array}$} \\
\hline & & & HR $(95 \%$ Cl) & \\
\hline \multicolumn{5}{|c|}{ Urological malignancy and all-cause mortality } \\
\hline Univariate model & $1.62(1.27-2.07)$ & $<0.001$ & $1.03(0.79-1.35)$ & 0.81 \\
\hline Multivariate model-1 & $1.26(0.98-1.62)$ & 0.06 & $1.05(0.81-1.38)$ & 0.70 \\
\hline \multicolumn{5}{|c|}{ Urological malignancy and end-stage renal disease } \\
\hline Univariate model & $1.08(0.80-1.47)$ & 0.59 & $1.12(0.80-1.58)$ & 0.49 \\
\hline
\end{tabular}

Multivariate Model-1: Adjusted for age, gender and ethnicity eGFR - estimated glomerular filtration rate calculated by CKD-EPI equation $H R$ Hazard ratio, $\mathrm{Cl}$ Confidence interval

cardiovascular disease-related mortality was low compared to the no malignancy CKD group (17.5\% versus $39.4 \%, p=0.006)$. The United States Renal Data System (USRDS) showed similar data in ESRD patients with renal malignancy, i.e. a higher cancer-specific mortality and a lower non-cancer specific mortality [20]. Renal outcomes including reaching ESRD and the RRT uptake were not different between the groups. In a study by Lee et al. in patients who had radical nephroureterectomy for upper tract urothelial carcinoma, those with low eGFR $\left(<60 \mathrm{~mL} / \mathrm{min} / 1.73 \mathrm{~m}^{2}\right)$ pre-operatively were more likely to experience complete recovery of renal function compared to patients with higher eGFR, and although counter-intuitive this was proposed to be due to compensatory hypertrophy of the surviving kidney [21].

In our cohort, urological malignancy did not show an independent association with all-cause mortality. A
Japanese CKD cohort with a predominance of urological malignancies had similar findings, with the presence of malignancy associated with malignancyassociated mortality (HR: 3.94; 95\% CI: $1.63-9.53 ; P=$ 0.002 ) but not all-cause mortality (HR: $1.34 ; 95 \%$ CI: $0.72-2.52 ; P=0.35$ ) [17]. However, our observational study included a much larger sample size compared to the Japanese cohort (2637 versus 515 patients). Kim et al. also developed a propensity score matched cohort study of Korean patients with renal cell carcinoma and showed that the presence of pre-operative CKD had a strong association with cancer-specific mortality (HR:1.62; $p=0.02$ ), but the association to all-cause mortality was close to losing significance (HR:1.45; $p=0.049$ ) [22].

The presence of urological malignancy was not associated with an increased risk of reaching ESRD and it did
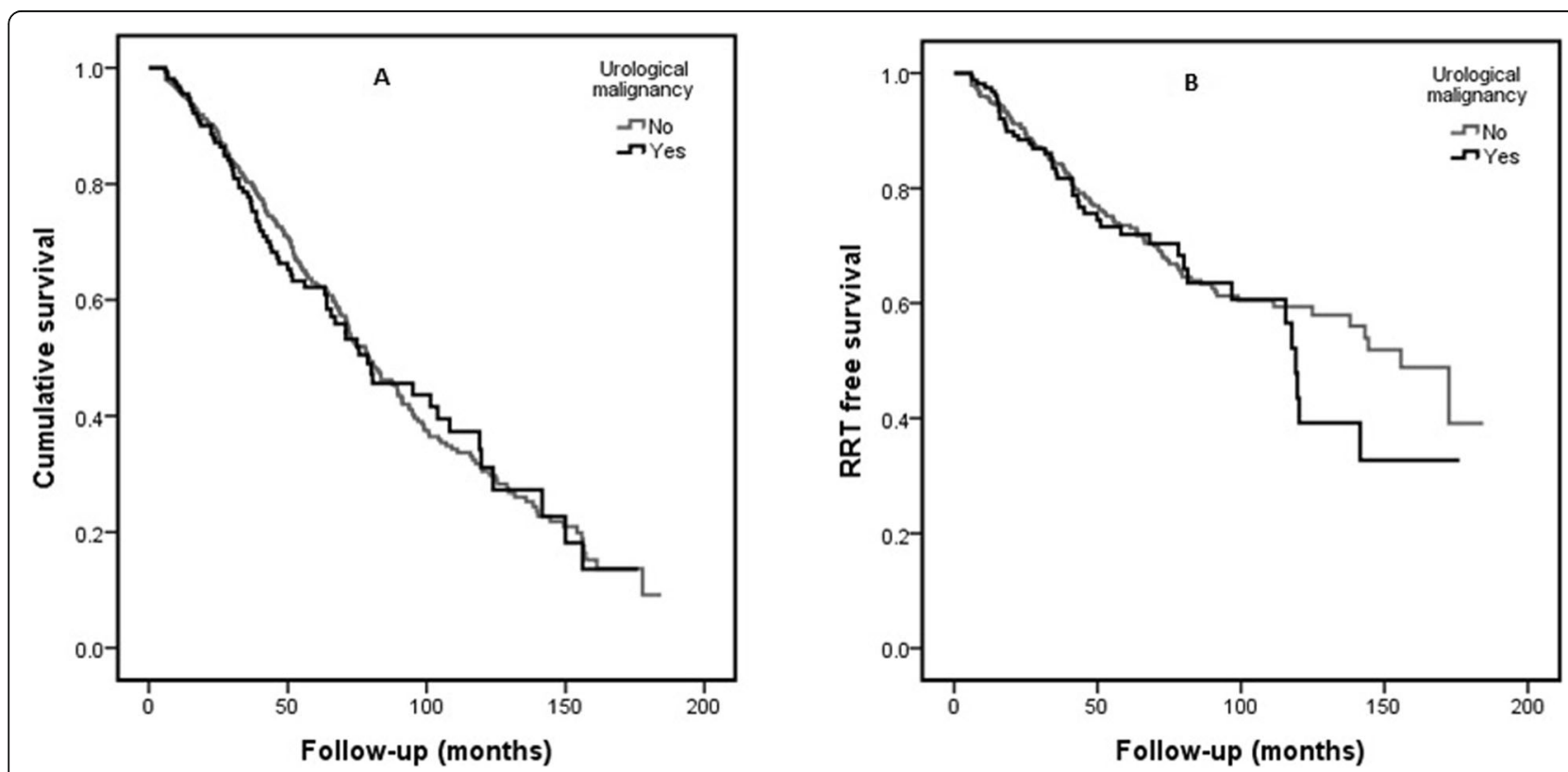

Fig. 4 Kaplan-Meier survival curve in the matched sample (a: all-cause mortality and panel b: RRT free survival) 
Table 4 Comparison of cumulative incidence of renal replacement therapy (RRT) and death at 5 and 10 years follow up between patients with urological malignancy and no malignancy in a competing risk model

\begin{tabular}{|c|c|c|c|c|c|c|c|}
\hline \multirow[b]{2}{*}{ Event } & \multirow[b]{2}{*}{ Time } & \multicolumn{3}{|l|}{ Total sample } & \multicolumn{3}{|l|}{ Matched sample } \\
\hline & & Urological malignancy (160) & No malignancy (2477) & $p$-Value & Urological malignancy (160) & No malignancy (480) & $p$-Value \\
\hline \multirow[t]{2}{*}{$\overline{\text { RRT }}$} & 5 years & 0.16 & 0.19 & & 0.16 & 0.13 & \\
\hline & 10 years & 0.22 & 0.26 & 0.28 & 0.22 & 0.18 & 0.30 \\
\hline \multirow[t]{2}{*}{ Death } & 5 years & 0.36 & 0.24 & & 0.36 & 0.33 & \\
\hline & 10 years & 0.57 & 0.44 & $<0.001$ & 0.57 & 0.59 & 0.81 \\
\hline
\end{tabular}

RRT-renal replacement therapy (haemodialysis, peritoneal dialysis and transplant)

Values represent cumulative incidence probability for events. $p$-Value by $\mathrm{X}^{2}$ statistics (Gray, 1988)

not accelerate the rate of progression of CKD (eGFR slope similar in both groups in the matched sample). In a meta-analysis of 58 studies, Patel et al. showed the overall rate of ESRD to be low (0.4-2.8\%) irrespective of the management strategy for renal cell carcinoma [23]. Moreover, a lower rate of renal functional decline was noted in patients with surgically induced CKD than in those patients with CKD from a medical cause who then underwent surgery [24].

In competing risk models, the cumulative probability of death was higher for patients in the UM group both at 5 years and 10 years. However, there was no difference in the cumulative incidence of progression to RRT. Demirjian et al. undertook a competing risk model in renal cancer surgery patients and showed that surgical CKD had a better prognosis than a combination of medical and surgical CKD in terms of renal function decline and mortality [25].

Our study is a single centre analysis of predominantly Caucasian patients who volunteered for participation in the cohort, and this warrants caution with respect to generalising the results to the entire CKD population. Non-availability of the CKD status of all the UM patients before the onset of malignancy restricted our ability to delineate the exact influence of CKD on the outcomes in patients with malignancy. Also, a large proportion of missing cause of death data limited the strength of investigating the association of UM with cancer-specific mortality. Despite these limitations, our study strengths included a robust database with large sample size and adequate follow-up data.

\section{Conclusion}

In conclusion, in our cohort of patients with advanced CKD, the presence of UM was not found to be associated with all-cause mortality. In addition, and independent of the management approach, the presence of UM did not prove to be a risk factor associated with worse renal outcomes (acceleration of the rate of CKD progression or reaching ESRD). Our study shows that the underlying medical causes of CKD, including diabetes and hypertension, may be the predominant influencers of the outcomes (renal and mortality) in patients with urological malignancies. A coordinated approach with early liaison between the urology and nephrology teams is needed in the management of UM patients with CKD in view of this, as the presence of UM did not appear to influence outcome. Future research to compare the outcomes in UM patients with and without the traditional cardiovascular risk factors including CKD can shed light on the risk stratification of these patients.

Table 5 Comparison of outcomes between the groups split based on date of cancer occurrence prior to recruitment and incident cancer

\begin{tabular}{llllll}
\hline Outcome & No malignancy (480) & $\begin{array}{l}\text { Malignancy history }>5 \text { years } \\
\text { Group A (47) }\end{array}$ & $\begin{array}{l}\text { Malignancy history <5 years } \\
\text { Group B (61) }\end{array}$ & $\begin{array}{l}\text { Concurrent/incident malignancy } \\
\text { Group C (52) }\end{array}$ & $\begin{array}{l}p \text {-Value } \\
\text { A vs C }\end{array}$ \\
\hline Death & $230(48 \%)$ & $19(40.4 \%)$ & $26(42.6 \%)$ & $25(48.1 \%)$ & 0.44 \\
Malignancy death & $0 / 111$ & $1 / 12(8.3 \%)$ & $5 / 14(35.7 \%)$ & $5 / 14(35.7 \%)$ & $0.17^{\mathrm{a}}$ \\
CVD death & $53 / 111(47.7 \%)$ & $1 / 12(8.3 \%)$ & $3 / 14(21.4 \%)$ & $3 / 14(21.4 \%)$ & $0.59^{\mathrm{a}}$ \\
ESRD & $131(27.3 \%)$ & $13(27.7 \%)$ & $17(27.9 \%)$ & $15(28.8 \%)$ & 0.89 \\
RRT & $72(15 \%)$ & $11(23.4 \%)$ & $9(14.8 \%)$ & $8(15.4 \%)$ & 0.31 \\
Renal transplants & $18(13.7 \%)$ & $1 / 13(7.7 \%)$ & $1 / 17(5.9 \%)$ & $2 / 15(13.3 \%)$ & $1.00^{\mathrm{a}}$ \\
\hline
\end{tabular}

Cause of death available only in 151/300 of matched sample

CVD cardiovascular disease, ESRD end-stage renal disease, $R R T$ renal replacement therapy

$p$-Value by Chi-square test. ${ }^{a} p$-Value by Fisher exact test 


\section{Supplementary information}

Supplementary information accompanies this paper at https://doi.org/10. 1186/s12882-020-01859-w.

Additional file 1: Table S1. Management strategies according to site of malignancy. Table S2. Association of urological malignancy with allcause mortality (Cox regression analysis- univariate model). Table S3. Association of urological malignancy with end-stage renal disease (Cox regression analysis- univariate model).

Additional file 2: Figure S1. Kaplan-Meier curve for all-cause mortality in the matched sample (A: comparison between groups split based on date of cancer occurrence prior to recruitment; B: comparison between groups split based on site of cancer).

\section{Abbreviations}

CKD: Chronic kidney disease; CRA: Competing risk analysis; EPR: Electronic patient records; ESRD: End-stage renal disease; eGFR: Estimated glomerular filtration rate; KM: Kaplan Meier; NFCVE: Non-fatal cardiovascular events; RAS: Renin-angiotensin system; RRT: Renal replacement therapy; SKS: Salford Kidney Study; UM: Urological malignancy

\section{Acknowledgements}

1. We extend our acknowledgements to all the research nurses involved in SKS data collection and management and all the study patients for consenting to participate in the study.

2. An abstract from the study was presented as a poster at the ERA-EDTA 2019 Congress.

\section{Authors' contributions}

Conception or design, or analysis and interpretation of data, or both-RC, PK Drafting the article or revising it -RC, PK. Providing intellectual content of critical importance to the work described- RC, NC, PK. Final approval of the version to be published- RC, NC, PK

\section{Authors' information}

RC: Senior Research Fellow (Renal Medicine), Salford Royal NHS Foundation Trust and University of Manchester.

NC: Professor of Urological Oncology, Salford Royal NHS Foundation Trust and The Christie NHS Foundation Trust, Manchester, UK; Director GenitoUrinary Research Group Paterson Institute; Director MCRC Pan-Manchester Biobank.

PK: Professor of Nephrology, Salford Royal NHS Foundation Trust and University of Manchester; Academic Vice President, UK Renal Association; Chair, NIHR Renal Disorders national group, National Institute for Health Research.

\section{Funding}

No financial support.

\section{Availability of data and materials}

The authors would not like to share the data as this study derives from a precious long-standing database in which data has been meticulously collected over 20 years. The authors are shortly planning to perform further analyses from the data, and these would be compromised if the database were made publically available but are available from the corresponding author on reasonable request.

\section{Ethics approval and consent to participate}

Salford Kidney Study has ethical approval obtained from the North West Greater Manchester South Research Ethics Committee, UK (current REC reference: 15/NW/0818) and all patients involved in our observational analysis have signed an informed consent.

\section{Consent for publication}

Not applicable.

\section{Competing interests}

No competing interest to declare.

\section{Author details}

'Department of Renal Medicine, Salford Royal NHS Foundation Trust, Salford M6 8HD, UK. 'Faculty of Biology, Medicine and Health, University of Manchester, Manchester, UK. ${ }^{3}$ Department of Urology, Salford Royal NHS Foundation Trust, Salford, UK. ${ }^{4}$ The Christie NHS Foundation Trust, Manchester, UK

Received: 30 April 2019 Accepted: 20 May 2020

Published online: 29 May 2020

\section{References}

1. Christensson A, Savage C, Sjoberg DD, Cronin AM, Frank O'Brien M, Lowrance W, et al. Association of cancer with moderately impaired renal function at baseline in a large, representative, population-based cohort followed for up to 30 years. Int J Cancer. 2013;133(6):1452-8.

2. Lowrance WT, Ordonez J, Udaltsova N, Russo P, Go AS. CKD and the risk of incident Cancer. J Am Soc Nephrol. 2014;25(10):2327-34.

3. Han Y, Shou D, Wen L, Shi J, Ding J, Gong P, et al. Interplay between chronic kidney disease (CKD) and upper tract urothelial carcinomas (UUC): foe or friend? Oncotarget. 2016:7(33):53951-8.

4. Chung SD, Huang KH, Lai MK, Huang CY, Chen CH, Pu YS, et al. CKD as a risk factor for bladder recurrence after Nephroureterectomy for upper urinary tract Urothelial carcinoma. Am J Kidney Dis. 2007;50(5):743-53.

5. Li CE, Chien CS, Chuang YC, Chang Yl, Tang HP, Kang CH. Chronic kidney disease as an important risk factor for tumor recurrences, progression and overall survival in primary non-muscle-invasive bladder cancer. Int Urol Nephrol. 2016;48(6):993-9.

6. Lane BR, Campbell SC, Demirjian S, Fergany AF. Surgically induced chronic kidney disease may be associated with a lower risk of progression and mortality than medical chronic kidney disease. J Urol. 2013;189(5):1649-55.

7. Weng P-H, Hung K-Y, Huang H-L, Chen J-H, Sung P-K, Huang K-C. Cancerspecific mortality in chronic kidney disease: longitudinal follow-up of a large cohort. Clin J Am Soc Nephrol. 2011:6(5):1121-8.

8. Ritchie J, Rainone F, Green D, Alderson H, Chiu D, Middleton R, et al. Extreme elevations in blood pressure and all-cause mortality in a referred CKD population: results from the CRISIS study. Int J Hypertens. 2013;2013:1-8.

9. Alderson HV, Ritchie JP, Pagano S, Middleton RJ, Pruijm M, Vuilleumier N, et al. The associations of blood kidney injury Molecule-1 and neutrophil Gelatinase-associated Lipocalin with progression from CKD to ESRD. Clin J Am Soc Nephrol. 2016;11(12):2141-9.

10. Noordzij M, Leffondré K, Van Stralen KJ, Zoccali C, Dekker FW, Jager KJ. When do we need competing risks methods for survival analysis in nephrology? Nephrol Dial Transplant. 2013;28(11):2670-7.

11. R Development Core Team. R: A Language and Environment for Statistical Computing. Vienna, Austria: the R Foundation for Statistical Computing; 2018. ISBN: 3-900051-07-0. Available online at https://cran.r-project.org/ mirrors.html. (Accessed 15 April 2019).

12. Scrucca L, Santucci A, Aversa F. Regression modeling of competing risk using R: an in depth guide for clinicians. Bone Marrow Transplant. 2010; 45(9):1388-95.

13. Gray RJ. A class of k-sample tests for comparing the cumulative incidence of a competing risk. Ann Stat 1988:16:1142-54.

14. Randolph JJ, Falbe K, Manuel AK, Balloun JL. A step-by-step guide to propensity score matching in R. Pract Assess Res Eval. 2014;19(18):1-6.

15. Hamano I, Hatakeyama S, Iwamura H, Fujita N. Preoperative chronic kidney disease predicts poor oncological outcomes after radical cystectomy in patients with muscle- invasive bladder cancer. Oncotarget. 2017;8(47): 83183-94.

16. Wu J, Suk-Ouichai C, Dong W, Antonio EC, Derweesh IH, Lane BR, et al. Analysis of survival for patients with chronic kidney disease primarily related to renal Cancer surgery. BJU Int. 2018;121(1):93-100.

17. Tanaka A, Inaguma D, Watanabe $Y$, Murata M, Shinjo H, Koike K, et al. Relationship between mortality and Cancer-bearing status in patients with chronic kidney disease who attended an educational program. Ther Apher Dial. 2018;22(1):49-57.

18. Zinger A, Cho WC, Ben-Yehuda A. Cancer and aging - the inflammatory connection. Aging Dis. 2017;8(5):611-27.

19. Gottlieb J, Higley C, Sosnowski R, Bjurlin MA. Smoking-related genitourinary cancers: a global call to action in smoking cessation. Rev Urol. 2016;18(4):194-204. 
20. Nguyen KA, Vourganti S, Syed JS, Luciano R, Campbell SC, Shuch B. Endstage renal disease secondary to renal malignancy: Epidemiologic trends and survival outcomes. Urol Oncol Semin Orig Investig. 2017;35(8):529.e1-7.

21. Lee BH, Zabor EC, Tennenbaum D, Furberg H, Benfante N, Coleman JA, et al. Renal function recovery after radical nephroureterectomy for upper tract urothelial carcinoma. World J Urol. 2018;36(2):257-63.

22. Kim YW, Kim WT, Yun SJ, Lee SC, Kim WJ, YS HA, et al. Preoperative chronic kidney disease status is an independent prognostic factor in patients with renal cell carcinoma. Ann Surg Oncol. 2015;22(12):4098-103.

23. Patel HD, Pierorazio PM, Johnson MH, Sharma R, lyoha E, Allaf ME, et al. Renal functional outcomes after surgery, ablation, and active surveillance of localized renal tumors: A systematic review and meta-analysis. Clin J Am Soc Nephrol. 2017;12:1057-69.

24. Lane BR, Demirjian S, Derweesh IH, Takagi T, Zhang Z, Velet L, et al. Survival and functional stability in chronic kidney disease due to surgical removal of nephrons: importance of the new baseline glomerular filtration rate. Eur Urol. 2015;68(6):996-1003.

25. Demirjian S, Lane BR, Derweesh IH, Takagi T, Fergany A, Campbell SC. Chronic kidney disease due to surgical removal of nephrons: relative rates of progression and survival. J Urol. 2014;192(4):1057-62.

\section{Publisher's Note}

Springer Nature remains neutral with regard to jurisdictional claims in published maps and institutional affiliations.

Ready to submit your research? Choose BMC and benefit from:

- fast, convenient online submission

- thorough peer review by experienced researchers in your field

- rapid publication on acceptance

- support for research data, including large and complex data types

- gold Open Access which fosters wider collaboration and increased citations

- maximum visibility for your research: over $100 \mathrm{M}$ website views per year

At $\mathrm{BMC}$, research is always in progress.

Learn more biomedcentral.com/submissions 